\title{
49,XXXXY syndrome: behavioural and developmental profiles
}

\author{
Cathy A Lomelino, Allan L Reiss
}

\begin{abstract}
Behavioural, psychological, and cognitive profiles of three cases, including a 5 year old male with a 49,XXXXY karyotype and a $(3 ; 15)$ translocation, a 9 year old male with a $49, X X X X Y$ karyotype, and a 32 year old male with $48, X X X Y / 49, X X X X Y$ mosaicism, are presented. Significant behavioural problems were seen in the two older patients. The degree of mental retardation and impairment of language abilities were shown to be more severe in the older subjects as well. These findings are discussed with respect to the effects of the $X$ chromosome on brain development.
\end{abstract}

Cases of sex chromosome aneuploidy are not uncommon and a broad spectrum of developmental outcome has been described. Since the first report of a patient with a 49,XXXXY karyotype by Fraccaro et $\mathrm{al}^{1}$ in 1960, a clinical description has been established for this syndrome. However, relatively little is known regarding the behavioural, psychological, and cognitive profile of these patients. Evidence indicates that despite $\mathrm{X}$ chromosome inactivation, an increased number of $\mathrm{X}$ chromosomes is associated with an increase in cognitive and language disability. ${ }^{2}$ This report describes three subjects with partial or complete $49, \mathrm{XXXXY}$ sex chromosome aneuploidy. Particular emphasis is placed on the severity and range of disability associated with this condition and the possible mechanisms by which it is produced.

Division of Child Psychiatry, Department of Psychiatry, Johns Hopkins University School of Medicine and The Kennedy Institute, Baltimore, MD, USA.

C A Lomelino, A L Reiss

Correspondence to Dr Reiss, Behavioral Genetics Unit, Room 507, 550 North Broadway, Baltimore, MD 21205, USA.

Received for publication 27 July 1990.

Revised version accepted for publication 5 January 1991.

\section{Methods}

The behaviour of our subjects was examined using a modified version of the Aberrant Behavior Checklist (ABC), ${ }^{3}$ which covers five aspects of behaviour frequently encountered in developmentally disabled persons: irritability and agitation, lethargy and withdrawal, stereotypy, hyperactivity and non-compliance, and inappropriate speech. The checklist was completed by both a parent and a teacher. Individual behaviour items were rated from 0 to 3 , according to the severity of the problem.

Language abilities were assessed through an interview with the parent(s) of the subject using the Vineland Adaptive Behavior Scale, Survey Form. ${ }^{4}$ Language impairments were also noted by observation.

Cognitive assessment using the Stanford Binet, 4th edition was performed on one subject at the time of evaluation. General cognitive ability was obtained for the other subjects from reports of previous testing.

\section{Case reports}

CASE 1

Case 1 was a 4 year 10 month old male with a karyotype of 49,XXXXY, t (3;15) (q29; q26.1) who was ascertained as a control subject for a research project. The translocation noted in this patient was also present in his mother, maternal uncle, and maternal grandfather. The maternal uncle was described as a slow learner with possible mild cognitive delays, although no formal diagnosis of mental retardation had been made. He weighed $2728 \mathrm{~g}$ at birth. His IQ was $78 \pm 6$ as measured by the Stanford Binet, 4th edition.

Case 1 was reported to have no significant behavioural problems. There were no significant findings from the ABC data. Vineland score in the communication domain was low with a mild deficit. Expressive subdomain score was low, while his receptive subdomain score was adequate. He had a statistically significant weakness in the communication domain when compared to his mean domain score. When compared to a National Standardization Sample, ${ }^{4}$ the difference between his communication domain score and mean domain score was found to fall in the extreme 16th centile, indicating significant weakness 
Clinical data for the three patients

\begin{tabular}{|c|c|c|c|}
\hline & Patient 1 & Patient 2 & Patient 3 \\
\hline $\begin{array}{l}\text { Age } \\
\text { Karyotype }\end{array}$ & $\begin{array}{l}4 \text { y } 10 \text { mth } \\
49, X X X X Y \\
t(3 ; 15)(q 29 ; q 26.1)\end{array}$ & $\begin{array}{l}9 \text { y } 5 \text { mth } \\
49, X X X X Y\end{array}$ & $\begin{array}{l}32 \mathrm{y} \\
48, \mathrm{XXXY} / 49, \mathrm{XXXXY}\end{array}$ \\
\hline $\begin{array}{l}\text { IQ } \\
\text { Behavioural problems }\end{array}$ & $\begin{array}{l}\text { Low average } \\
\text { None }\end{array}$ & $\begin{array}{l}\text { Mild MR } \\
\text { Irritability/agitation, } \\
\text { hyperactivity/non-compliance, } \\
\text { inappropriate speech }\end{array}$ & $\begin{array}{l}\text { Moderate MR } \\
\text { Irritability/agitation, } \\
\text { lethargy/withdrawal, } \\
\text { stereotypy, } \\
\text { hyperactivity/non-compliance, } \\
\text { inappropriate speech }\end{array}$ \\
\hline $\begin{array}{l}\text { Vineland } \\
\text { Communication domain }\end{array}$ & $\begin{array}{l}\text { Low } \\
\text { Mild deficit, } \\
\text { low expressive, } \\
\text { normal receptive }\end{array}$ & $\begin{array}{l}\text { Low } \\
\text { Moderate deficit, } \\
\text { low expressive, } \\
\text { low receptive }\end{array}$ & $\begin{array}{l}\text { Low } \\
\text { Profound deficit, } \\
\text { low expressive, } \\
\text { normal receptive }\end{array}$ \\
\hline
\end{tabular}

in communication skills as compared to other overall developmental abilities.

\section{CASE 2}

Case 2 was a 9 year 5 month old white male with a 49,XXXXY karyotype. At birth he weighed $1936 \mathrm{~g}$. His IQ was in the mildly mentally retarded range.

His family history was significant for depression. He had a long history, beginning around the age of 6 , of disruptive and oppositional behaviour, irritability, and temper tantrums. Problems with selfcontrol and impulsivity were present and included aggression with peers such as throwing things, hitting, kicking, and pinching. On the ABC, case 2 was rated by his parent and teacher as having significant behaviour problems in the following areas: irritability and agitation, hyperactivity and non-compliance, and inappropriate speech.

Speech contained significant problems with dysarticulation. Vineland Adaptive Behavior score was low with a moderate deficit in the communication domain. A statistically significant weakness in the communication domain was noted when compared to the mean domain score. The difference between his communication domain score and the mean domain score represented a difference seen in only the extreme $5 \%$ of the National Standardization Sample, ${ }^{4}$ indicating a significant weakness in communication ability as compared to his general developmental functioning.

\section{CASE 3}

Case 3 was a 32 year old male with a $48, \mathrm{XXXY}$ / $49, \mathrm{XXXXY}$ karyotype. He weighed $1496 \mathrm{~g}$ at birth. His IQ was in the moderately mentally retarded range.

Case 3 suffered from recurrent episodes of dramatic change in mental status involving psychomotor behaviour, affect, social withdrawal, self-injury, and possible psychotic symptoms. He also showed problems with self-control, including grabbing at people. Parent ABC data, rated during times of adverse change in mental status, showed extreme behaviour problems in the following areas: irritability and agitation, lethargy and social withdrawal, hyperactivity and non-compliance, and inappropriate speech. Stereotypic behaviour was also a serious problem. Teacher ABC data, rating overall behaviour, showed extreme problems with inappropriate speech.

He exhibited abnormal speech form and content. His score in the Vineland communication domain was low with a profound deficit. Expressive subdomain score was low, while receptive subdomain score was adequate. A statistically significant weakness in the communication domain was noted in comparison to the mean domain score. This difference between the communication domain score and mean domain score represented a difference found in orily 1 to $5 \%$ of the National Standardization Sample.4 This indicates a severe deficit in communication ability as compared to general developmental abilities. A summary of the clinical data for all three patients is shown in the table.

\section{Discussion \\ COGNITIVE DEVELOPMENT}

Borghgraef $e t a l^{5}$ reported a widespread variation of intellectual performance in $49, \mathrm{XXXXY}$ syndrome with IQ ranging from 20 to 70 with a mean of 35 ; the majority of adult patients fell in the moderate to severe range of mental retardation. For the patients described in this report, the youngest subject had an IQ of $78 \pm 6$ as measured by the Stanford Binet, 4th edition, showing that IQ in this population can fall in the low average range. Shapiro et al, ${ }^{6}$ Schmidt et $a l{ }^{7}$ and Borghgraef $e t \mathrm{al}^{5}$ noted a decline in intellectual development with age in $49, \mathrm{XXXXY}$ males.

In our report, language impairment and degree of mental retardation appeared to be most severe in the older subjects. Although this cross-sectional evaluation cannot definitely address the issue of intellectual decline in $49, \mathrm{XXXXY}$ syndrome, our findings suggest the need for other longitudinal investigations. 


\section{BEHAVIOUR}

Patients with 47,XXY karyotype have been described by Walzer et $a l^{8}$ as exhibiting low activity, low intensity of responsiveness, and high withdrawal, especially from new situations. Stewart et $a l^{2}$ described 47,XXY patients as less social, less assertive, and less active than $46, \mathrm{XY}$ males. These patients have also been described as having problems with impulsivity and self-control. ${ }^{10}$ Subjects with $49, \mathrm{XXXXY}$, which is often considered a variant of the $47, \mathrm{XXY}$ syndrome, have been noted as exhibiting behavioural problems, but no consistent profile has been described. Borghgraef et $a l^{5}$ described $49, \mathrm{XXXXY}$ patients as very timid and shy, with low frustration tolerance and very anxious reactions to minor charges. Stereotyped language and hyperactivity were also described. Of the patients described in our report, cases 2 and 3 were shown to exhibit serious behavioural problems, especially in the areas of irritability and agitation, hyperactivity and noncompliance, and inappropriate speech. However, in this study, cases 2 and 3 were both ascertained after referral for evaluation of behavioural problems. As previously noted, case 1 was ascertained as a control subject for a research project and was shown to exhibit no behavioural problems on the ABC. Therefore, behavioural problems in the two older subjects may not be representative of the general $49, \mathrm{XXXXY}$ population. However, case 2 did not exhibit major behavioural difficulties until an age at which the demands of a structured setting were encountered. This suggests that our youngest subject, case 1 , may have not yet reached an age at which behavioural problems are exhibited.

\section{TRANSLOCATION}

Ockey and de la Chapelle ${ }^{11}$ and de la Chapelle and Schroder $^{12}$ described a $49, \mathrm{XXXXY}$ male with a balanced 4;11 translocation. The translocation was inherited and present throughout the family members. The patient showed no clinical abnormality other than that characteristic of $49, \mathrm{XXXXY}$ syndrome. In this study, case 1 was shown to have an inherited $3 ; 15$ translocation that appeared to be balanced. There seems to be no evidence of a relationship between the presence of a translocation as shown in these two subjects and the occurrence of the $49, \mathrm{XXXXY}$ karyotype.

\section{LANGUAGE}

Poor language development is well documented in cases of excess $\mathrm{X}$ chromosome material. It has been shown that anomalous numbers of $\mathrm{X}$ chromosomes are associated with specific deficits in intellectual ability. A study of the intellectual abilities of children with excess $\mathrm{X}$ chromosomes by Netley and
Rovet ${ }^{13}$ showed a significant deficit in verbal ability, while non-verbal skills were intact. Rovet and Netley $^{14}$ found a group of trisomy $\mathrm{X}$ girls to be deficient in verbal skills. They found greater impairments with verbal tasks than with spatial tasks. In the case of deficient amounts of X chromosome material (that is, $45, \mathrm{X}$ Turner's syndrome), the opposite pattern of ability, defined by a marked spatial deficit with normal verbal skills, has been reported. ${ }^{13}$ Similar results were stated by Money, ${ }^{15}$ who reported that when verbal and performance values are compared, it is found that subjects with sex chromosome monosomy $(45, X)$ have a lower performance IQ than verbal IQ. These studies seem to suggest that as the number of excess $X$ chromosomes increases the severity of verbal impairment also increases.

In a study of $47, \mathrm{XXY}$ males, Graham et $a l^{16}$ described greater impairment in language production than in language comprehension. These findings suggest a relation between the amount of $X$ chromosome material and the relative development of verbal and non-verbal abilities. These authors report that specific deficits in expressive language may be indicative of left hemisphere dysfunction that results from the reversal of the usual left-right asymmetry of the brain, leaving the left hemisphere anatomically ill suited to perform language functions.

Severe retardation in language development in $49, \mathrm{XXXXY}$ patients has been described by Borghgraef et $a l^{5}$ and others. Moric-Petrovic et $a l^{17}$ described a significant discrepancy between expressive ability and comprehension in these patients. In our study, all three patients with the $49, \mathrm{XXXXY}$ karyotype were found to have a significant deficit in language abilities. Cases 1 and 3 were shown to have low expressive language skills while their receptive language skills were adequate according to the Vineland Scale.

Netley and Rovet ${ }^{13}$ have suggested that in cases of a supernumerary $\mathrm{X}$, slow rates of prenatal neuronal growth selectively retard the development of the left hemisphere, thereby disturbing the normal process of hemispheric lateralisation, specifically the specialisation of the left cerebral hemisphere for language functioning. This hypothesis (along with that presented by Graham et $a^{16}$ ) may explain the severe language disorder found in the $49, \mathrm{XXXXY}$ subjects in this study. Recent evidence indicates that noncontiguous genes on the $\mathrm{X}$ chromosome escape the normal processes leading to inactivation and remain capable of genetic expression. ${ }^{18}$ Therefore, gene dosage effects may cause disruption of specific aspects of brain development in subjects with $\mathrm{X}$ chromosome aneuploidy.

This study was supported in part by grant MH00726 from the National Institute of Mental 
Health, grants HD25806 and HD24061 from the National Institutes of Health, and a grant from the John Merck Fund.

1 Fraccaro M, Kaijser K, Lindsten GJ. A child with 49 chromosomes. Lancet 1960;ii:899-902.

2 Stewart DA, Bailey JD, Netley C, Rovet J, Park E. Growth and development from early to midadolescence of children with $\mathrm{X}$ and $\mathrm{Y}$ chromosome aneuploidy: the Toronto study. Birth Defects 1986;22(3):119-82.

3 Aman MG, Singh NN. Aberrant behavior checklist. New York: Slosson Educational Publications, 1986.

4 Sparrow S, Balla DA, Cicchetti DV. Vineland Adaptive Behavior Scale, Survey Form. Circle Pines, Minnesota: American Guidance Service, 1984.

5 Borghgraef M, Fryns JP, Smeets E, Marien J, Van den Berghe $\mathrm{H}$. The 49,XXXXY syndrome. Clinical and psychological follow-up data. Clin Genet 1988;33:429-34.

6 Shapiro LR, Brill CB, Hsu LY, Calvin ME, Hirschhorn K. Deceleration of intellectual development in a XXXXY child. Am ₹ Dis Child 1971;122:163-4.

7 Schmidt R, Pajewski M, Rosenblatt M. Epiphysial dysplasia: a constant finding in the XXXXY syndrome. $f$ Med Genet 1978;15:282-7.

8 Walzer S, Bashir AS, Graham JM Jr, et al. Behavioral development of boys with $X$ chromosome aneuploidy: impact of reactive style on the educational intervention for learning deficits. Birth Defects 1986;22(3):1-21.
9 Burnard G, Hunter H, Haggart K. Some psychological test characteristics of Klinefelter syndrome. Br $\mathcal{f}$ Psychiatry 1967;113:1091-6.

10 Jablensky AJ, Janota J, Sheperd M. Neuropsychiatric illness and neuropathological findings in a case of Klinefelter syndrome. Psychol Med 1970;1:18-29.

11 Ockey $\mathrm{CH}$, de la Chapelle A. Autoradiographic re-appraisal of an XXXXY male as a probable XXXXY with a 4/11 translocation. Cytogenetics 1967;6:178-92.

12 De la Chapelle A, Schroder J. Autoradiographically identified karyotype $49, \mathrm{XXXXY}, \mathrm{t}(4 ; 11)$ (q35;q23) confirmed by banding. Hereditas 1973;74:291-2.

13 Netley C, Rovet J. Verbal deficits in children with 47, XXY and 47,XXX karyotypes: a descriptive and experimental study. Brain Lang 1982;17:58-72.

14 Rovet J, Netley C. The triple X chromosome syndrome in childhood: recent empirical findings. Child Dev 1983;54:83145.

15 Money J. Cytogenetic and psychosexual incongruities with a note on space-form blindness. Am $\mathcal{F}$ Psychiatry 1963;119:8207.

16 Graham JM, Bashir AS, Stark RA, Silbert A, Walzer S. Oral and written language abilities of XXY boys: implications for anticipatory guidance. Pediatrics 1988;81:795-806.

17 Moric-Petrovic S, Laca Z, Markovic S, Markovic V. $49, \mathrm{XXXXY}$ karyotype in a mentally retarded boy. $\mathcal{f}$ Ment Defic Res 1973;17:73-80.

18 Page DC, Disteche CM, Simpson EM, et al. Chromosoma localization of ZFX - a human gene that escapes $X$ inactivation - and its murine homologs. Genomics 1990;7:37-46. 